\title{
Entre la piedad y la obscenidad. Una tensión frente al dolor del otro
}

\section{Between mercy and obscenity. A tension facing pain of others}

Prof. Federica Scherbosky'

\begin{abstract}
Resumen:
El presente trabajo presenta un análisis acerca de la representación estética del dolor, temática ésta que puede ser estudiada tanto desde el punto de vista del artista, como así también desde el espectador. ¿Cómo se representa el dolor?, ¿qué nos mueve a ver una representación estética de este tipo?, ¿qué se produce frente al dolor de los demás?, son algunas de las preguntas que atraviesan el análisis.

Se considera que determinadas perspectivas de la piedad y de la obscenidad pueden ser orientadoras en la búsqueda de respuestas, de allí que se aborden también estos conceptos.

Finalmente se sostiene que frente a la tensión marcada entre avasallamiento e indiferencia la representación estética puede ser un modo propicio de relacionarse con el dolor del otro de un modo diferente.
\end{abstract}

Palabras clave: piedad - obscenidad - dolor - otro - representación estética

\begin{abstract}
:
The present article analyzes the esthetic representation of pain, topic that may be studied from the artist as well as from the spectator point of view. How is pain represented?, what move us to see an esthetic representation of this kind?, what is produced facing pain of others?, are some of the questions that cross the analysis.

It is considered that some perspectives of mercy and obscenity may be oriented to answer some questions. That is the reason why those concepts are considered.

Finally, it is sustained that in front of the tension marked between trampling and indifference of the esthetic representation can be a proper way to be related to the pain of others in a different manner.
\end{abstract}

Key words: Mercy - obscenity - pain - other - esthetic representation

\footnotetext{
1 Argentina. Profesora de Filosofía por la Universidad Nacional de Cuyo, Mendoza, Argentina. Actualmente realiza su doctorado en la Facultad de Filosofía y Letras de la Universidad de Buenos Aires. Becaria de CONICET. Lugar de trabajo: Instituto de Filosofía, FFyL, UBA. fedescherbo@yahoo.com.ar
} 
Hace dos años, durante los primeros días que siguieron a nuestro retorno, fuimos todos, creo, presas de un verdadero delirio. Queríamos hablar, ser escuchados al fin. Nos dijeron que nuestra apariencia física ya era bastante elocuente por sí sola. Pero recién volvíamos, traíamos con nosotros nuestra memoria, nuestra experiencia viva aún y sentíamos el deseo frenético de decirla tal cual era. Y, sin embargo, ya desde los primeros días, nos parecía imposible colmar la distancia que íbamos descubriendo entre el lenguaje del que disponíamos y esa experiencia que seguíamos viviendo casi todos, en nuestros cuerpos. (...) Esa desproporción entre la experiencia que habíamos vivido y el relato que era imposible hacer a partir de ella se confirmó definitivamente más adelante. Estábamos efectivamente frente a una de esas realidades de las que se dice que sobrepasan la imaginación. Quedaba claro entonces que sólo por elección, es decir una vez más, gracias a la imaginación, podríamos intentar decir algo.

"La Especie Humana", Robert Antelme.

Varias serían las preguntas que podríamos plantearnos cómo guías del presente trabajo, pero debemos primeramente aclarar que éstas provienen de la reflexión acerca de la representación estética del dolor. No es un cuestionamiento acerca de la posibilidad o no de la misma, sino sobre las reflexiones que esta "bella" representación del dolor genera, cuáles son las tensiones teóricas, pero por qué no también aquellas prácticas que en su proceso se originan.

Se abren en primer lugar dos grandes aspectos para su análisis: el ámbito propio del artista que crea la representación -¿Cómo se representa el dolor propio o ajeno?-y el del espectador que la observa. Aquí no se puede evitar la pregunta acerca de por qué miramos el dolor del otro, ¿qué nos lleva a ver algo trágico, doloroso? Y a partir de allí ¿qué significa mirar el dolor de los demás?

Este es el recorrido que pretendemos emprender para finalmente situarnos en esta última parte, en la tensión que se produce cuando nos detenemos frente al dolor del otro. Piedad y obscenidad son las formas en que creemos se presenta esta tensión, de allí que intentaremos una explicación de las mismas. 
Al pensar en la piedad son varios los recorridos que podrían hacerse a lo largo de la historia de la filosofía. Podemos rastrearla en muchos otros autores, como por ejemplo en el De Pietatis de Philodemus, o en el De Natura Deorum de Cicerón, aunque al analizar estas obras se observa que su tratamiento se enmarca dentro de un ámbito más bien teológico. Aquí se hace referencia a la relación que establecen los hombres con los dioses, y donde se define la piedad como la justicia para con éstos. No es por aquí por donde se quiere encauzar el presente escrito, por lo cual decidimos partir de Rousseau y de su análisis ético-político.

De igual modo se considera importante dejar en claro una distinción terminológica que podría llevar a confusión sobre todo en el uso de la lengua española, ya que se utiliza el vocablo piedad en los dos sentidos arriba diferenciados. Podemos pensar la piedad en sentido más bien teológico, lo que se indica en inglés con la palabra piety y en francés con la palabra pieté, mientras que si queremos hacer referencia a la piedad en una concepción ética del término en inglés estaríamos hablando de pity, y en francés de aquello que se designa bajo el término de pitié. Pity-piety y pitié-pieté denotan un juego semántico que no es posible observar en español. De allí que pretenda dilucidarse esta posible confusión desde el comienzo, para avanzar a partir de aquí en este estudio de la piedad, pero en el sentido ético del término.

Así más allá de las diversas perspectivas de análisis posibles decidimos enmarcarnos en el estudio que Rousseau hace de la misma y específicamente en su Discurso sobre el origen y los fundamentos de la desigualdad entre los hombres.

Para el autor la piedad es un sentimiento natural, que junto con la autoconservación conforman el núcleo básico natural del hombre. Éstas son disposiciones naturales que también encontramos en los 
animales, por lo que no es sólo este núcleo lo que persigue y lo que lo define humanamente, sino su perfectibilidad.

Como nos dice el autor:

Hablo de la piedad, disposición conveniente a seres tan débiles y sujetos a tantos males como lo estamos nosotros; virtud tanto más universal y tanto más útil al hombre cuanto que ella antecede en él al uso de toda reflexión y tan natural que las mismas bestias nos dan a veces signos sensibles de ella ${ }^{2}$

Esta disposición es virtud universal previa a la razón. Ella será la fuente de todas las demás virtudes, sobre todo de aquellas sociales como la generosidad, la clemencia, etc. Por lo cual sostiene Rousseau que los hombres serían monstruos si no estuvieran dotados de piedad en apoyo a su razón. No sería posible enfrentarse a la debilidad misma del hombre, a sus ínsitos males, a sus propias desdichas con la sola ayuda de la razón. Necesita por esto una vía de acceso y de comprensión a aquello que escapa a la racionalidad, la debilidad misma que nos conforma.

Incluso es tanto más profunda esta constitución que se la atribuye a los mismos animales. Tanto más natural como el mismo lo menciona, que las mismas bestias nos dan signos de ella. En las bestias también encontramos este núcleo de piedad y autoconservación, y es lo que posibilita el equilibrio de la existencia.

Aclara, sin embargo, que tal sentimiento surge en el estado que él considera como "de perfecta libertad", en el Estado de Naturaleza. Ella aparece como uno de los principios anteriores a la razón y a la cultura; y no depende de una toma de decisión, de un momento en el que intervenga la voluntad para que ésta acontezca. Surge sin más, como un simple sentimiento, como una disposición natural.

2 ROUSSEAU, J.J. Discurso sobre el origen y los fundamentos de la desigualdad entre los hombres. Tecnos. Madrid. 1995. pág. 149. 
No obstante, aunque la piedad parezca desvanecerse con la pérdida del Estado de Naturaleza y con el consecuente devenir del estado de corrupción del hombre, su potencia se encuentra siempre allí. Ésta perdura y actúa cuando el hombre se pervierte, o sea cuando ingresa a la sociedad civil. De hecho es allí cuando más encuentra su expresión, ya que a pesar de la corrupción del hombre mismo, sigue experimentándose una repugnancia innata frente al dolor de otro. Hay algo que pone un límite al propio bienestar y que abre la mirada al otro sufriente. Es nada menos que el sentimiento de la piedad. En palabras rousseaunianas:

Hay (...) otro principio (...) que habiendo sido dado al hombre para dulcificar en determinadas circunstancias la ferocidad de su amor propio o el deseo de conservación antes del nacimiento de éste, modera o disminuye el ardor que siente por su bienestar a causa de la repugnancia innata que experimenta ante el sufrimiento de sus semejantes, (es) la única virtud natural. ${ }^{3}$ Es la piedad la respuesta frente a este sentimiento de repugnancia innata a ver sufrir a un semejante debido a la existencia, en cada uno, del amor a sí mismo. ${ }^{4}$

Debemos aclarar aquí que hay una diferencia entre lo que Rousseau postula como el amor propio y el amor de sí. El amor de sí es un sentimiento que se presenta en el hombre natural que conlleva a la autoconservación, mientras que al hombre social lo caracteriza el amor propio.

No debe confundirse el amor propio con el amor a sí mismo (...) El amor a sí mismo es un sentimiento natural que lleva a todo animal a velar por su propia conservación, y que, dirigido en el hombre por la razón y modificado por la piedad, produce o engendra el sentimiento de humanidad

3 ROUSSEAU, J.J. Obras Escogidas. Ed. El Ateneo. Buenos Aires. 1950. pág. 768-769.

4 Ibídem, pág. 742. 
y el de virtud. El amor propio no es más que un sentimiento relativo, ficticio y nacido en la sociedad. ${ }^{5}$

Lo que buscará analizarse, será este amor a sí mismo, que es lo que se considera innato, que se regula por medio de la razón y la piedad y engendra humanidad y virtud. Este es el núcleo central para el autor, que posibilita no sólo la propia existencia sino la apertura a los demás, tanto como límite de uno mismo, como de ayuda, socorro y comprensión al otro.

La piedad, a partir de este análisis, es una de las cualidades del alma humana que desde la perspectiva de Rousseau nos permitiría colocarnos en el lugar del ser de nuestra misma especie que sufre. Ésta existe como "puro movimiento de la Naturaleza", como parte de este natural sentimiento de amor a sí mismo, e implica una acción física, un desplazamiento, un transporte del alma hacia el que sufre. En esta instancia no es una acción moral, sino un mero movimiento natural -aunque pueda luego volverse moral-. La autolimitación de la piedad, de este ir hacia el que sufre es parte necesaria de la autoconservación; siempre y cuando no me exponga a la muerte surge este desplazamiento hacia el otro.

De hecho Fernando Savater analiza la piedad y la equipara a la compasión. Sostiene que es ésta la raíz de la formación de lo humano en cuanto primera apertura hacia los demás, es el rasgo más característico, siendo 'compasión' y 'piedad' sinónimos ante el sufrimiento del otro. Es el correctivo más humanamente natural de los excesos del artificioso amor propio ${ }^{6}$, ya que este último surge con el ingreso a la sociedad civil, al generarse una comparación con sus semejantes que ahora son fuente de diferencia.

5 Ibídem, Pág. 846.

6 SAVATER, F. "La humanidad en cuestión", en La secularización de la Filosofía. Hermenéutica y posmodernidad. Gedisa Editorial. Barcelona.1992. pág. 263-266. 
Desde esta perspectiva la piedad genera un mecanismo que nos "permite" colocarnos en el lugar de otro, donde para compadecerme de quien sufre debo verlo como una variedad simplemente aparente, en realidad otra manifestación de lo que yo soy. ${ }^{7}$

Aquí encontramos un escollo en el que no adherimos a la idea de Rousseau, puesto que creemos que la piedad no puede sostenerse en la identificación, o no por lo menos tan directamente. Habría que pensar que el otro es otro más allá de lo que uno sea, que su dolor es válido y genuino más allá de que se logre la identificación con él o de que éste entre en nuestros parámetros, en nuestros modos de percibir la realidad. La piedad debería surgir por la alteridad sufriente del otro en cuanto tal y no por el horizonte de la mismidad en el que nos identificamos.

No obstante, reafirma Rousseau:

Aun cuando fuese verdad que la compasión es un sentimiento que nos pone en el lugar del que sufre, sentimiento oscuro y vivo en el hombre salvaje, desarrollado pero débil en el hombre civil, ¿qué significaría esta idea para lo que yo digo, si no es darle más fuerza? Efectivamente, la compasión sería tanto más enérgica cuanto el animal espectador se identificase más íntimamente con el animal que sufre. Ahora bien, es evidente que esta identificación ha debido ser infinitamente más estrecha en el estado de naturaleza que en el estado de raciocinio. ${ }^{8}$

Aquí el autor hace una diferenciación tanto en el grado de la piedad como en el de la identificación, dándoles a su vez correspondencia. Implica entonces que en el estado de naturaleza la piedad sería más viva -aunque también más oscura- y la identificación más estrecha que en el hombre inmerso en la sociedad. Sin embargo continúa

GOLDWASER YANKELEVICH, Natalie. La Piedad: excusa para un diálogo mejor. 2005. En http://www.a-r-w-e-b.com.ar/isociologia (12/12/09), pág. 136. 8 ROUSSEAU, J.J. Discurso sobre el origen y los fundamentos de la desigualdad entre los hombres. Tecnos. Madrid. 1995. pág. 151. 
afirmando la existencia de la misma en el hombre civilizado, ahora como un sentimiento desarrollado, "educado". No estaríamos ante una aporía en la que el hombre perdería la piedad y el amor a sí mismo junto con su Estado de Naturaleza, sino que es posible un desarrollo de la misma y una recuperación de aquella pasión pero sólo a través de un aprendizaje en donde debe prevalecer la imaginación.

La piedad sería ahora una virtud ética, pudiendo sólo brotar del amor propio que, como sostenía anteriormente, y siguiendo la explicación de Starobinski -estudioso de Rousseau- no sería fruto de una identificación espontánea con los seres dolientes, como lo hacía el hombre de la naturaleza, sino tomando distancias y contemplando el espectáculo de la existencia humana.

El sentimiento natural de la piedad, que conformaba el amor a sí mismo, es dejado de lado en pro de un primer distanciamiento con el otro. No implica por ello un cierre, una no comprensión o no acudir en su socorro, sino una nueva relación que se detiene ante el sufrimiento ajeno. Ya no esta disposición natural que llama a un inmediato desplazamiento, incluso físico. Ahora se produce distanciamiento, observación y escucha.

Habría aquí una modificación de una piedad en tanto disposición natural hacia una virtud ética, aprendida, reflexionada y que ya no supone una inmediata y estrecha identificación con el otro, sino en principio una distancia. En este juego de distancia y acercamiento, de ida y vuelta hacia el otro en su dolor, no cabría ya la posibilidad de un movimiento hacia una total unión sin fisuras. No sería posible esta unidad homogénea, puesto que en el fondo la identificación no generaba una unión sino una imposición, un avasallamiento del dolor del otro.

II

Con respecto a la obscenidad decidimos alejarnos, por lo menos primeramente, del significado habitual, de aquel que podemos recoger 
en cualquier diccionario en el sentido de impúdico, torpe, ofensivo al pudor, ${ }^{9}$ para volcarnos hacia uno de sus posibles análisis etimológi$\cos ^{10}$. La elección del mismo se sustenta en que esta posible etimología nos llevará de regreso al campo de la representación.

Parece ser que tanto los griegos como los romanos tenían un claro sentido de la obscenidad, puesto que si seguimos esta posible etimología se trataría de un concepto surgido en el teatro.

Cuidaban los trágicos que aunque a lo largo del drama se tuviese puntual noticia de las escenas más crudas, éstas nunca se representasen ante el público, sino ob scaenam, fuera de la escena, en la parte de atrás, de modo que los espectadores pudieran oír, pero no ver los crímenes. Saber de ellos, intuirlos, adivinarlos, pero jamás presenciarlos.

Era una norma no sólo de buen gusto, sino de efecto escénico, no podía arriesgarse el dramaturgo a arruinar el atractivo del protagonista presentándolo en su actitud más repugnante. Así, actuaba detrás de la escena, iluminada, y sólo se veían las sombras y se oía el alboroto que acompañaba el asesinato del antagonista, siendo ésta la escena más cruda de la obra.

El dramaturgo se alejaba también de este modo del crimen, al paso que generaba a su vez una especie de protección para el puebloespectador de aquello que no debía ser visto. Podía ser contraproducente el regodeo en el crimen y en la sangre, aunque se derramase oportunamente. Así, se trataba de mantener a éstos en las sombras, bajo la obscenidad, o sea fuera de escena. Cada uno debía traducir las sombras y los gemidos de la víctima según su conciencia. Si bien la tragedia se presentaba como una instancia formativa de las pasio-

9 Fuente consultada: Diccionario de la Real Academia Española online. www.rae.es 10/08/2010.

10 El diccionario de Lewis \& Short conjetura: [perh. ob and caenum, filth] Quizás de ob + caenum, inmundicia, basura. Aunque no hay certeza acerca de la etimología. 
nes, no se generaba una visión directa de estos hechos criminales o sangrientos, sino que se velaban, abriendo así una distancia con el horror representado.

Lo obsceno era mostrar aquello que los códigos sociales, la cultura y el buen gusto no les permitía ver. Quizás también porque dentro de los parámetros de la obra excedía lo que podríamos pensar como una representación justa. La desmesura -hibris- propia ya de la obra trágica, no permitía un doble desbordamiento como podría haber implicado esta visibilidad del horror.

\section{III}

Luego de haber expuesto desde dónde nos posicionamos a la hora de pensar conceptos como la piedad y la obscenidad volvemos al tema que nos atañe sobre la representación estética del dolor.

Intentaremos aquí situarnos en la posición de espectador con la aspiración de abrir -de hacer camino en- algunas preguntas en relación al dolor del otro, ¿qué nos lleva a ver algo trágico, doloroso? Y a partir de allí, ¿qué significa mirar el dolor de los demás?

Apelamos nuevamente a la lectura de la piedad de Rousseau ya que éste afirma una especie de búsqueda de experimentación de la piedad, como un sentimiento del cual se goza. Se busca la representación del dolor para que se ponga en ejercicio el mecanismo de la piedad, como bien plantea en esta carta, en respuesta al cuestionamiento de Philopolis.

"¿Por qué la plebe, a quien Rousseau concede una tan alta dosis de piedad, se alimenta con tal avidez del espectáculo de un desgraciado que muere sobre la rueda? ${ }^{11 "}$ Por la misma razón por la que vos vais a llorar al teatro y a ver a Seide ${ }^{12}$

11 Cursivas en el original, haciendo referencia a la pregunta de Philopolis en la carta que antecede a esta respuesta.

12 Seide: personaje de Mahomet, tragedia escrita por Voltaire en 1741. 
ahorcar a su padre, o a Thyeste 13 beber la sangre de su hijo. La piedad es un sentimiento tan delicioso que no es nada extraño que se busque gozar de él. Por lo demás, cada cual tiene una curiosidad secreta por estudiar los movimientos de la naturaleza en las proximidades de ese momento temible que nadie puede evitar. Añadid a esto el placer de ser durante dos meses el orador del barrio y relatar patéticamente a los vecinos la bella muerte del último ajusticiado. ${ }^{14}$

Debemos destacar aquí que el autor sitúa la problemática dentro del campo de la representación, ejemplificándolo particularmente con el teatro. Así postula un cierto gozo dentro de la situación de dolor que se sucede y que sirve de disparador del sentimiento de la piedad. La representación se figura a modo de ejercicio, no sólo en lo que a la piedad específicamente atañe, sino también como un modo de satisfacción de curiosidad sobre el dolor, la muerte, la enfermedad, lo trágico. Entran en juego en la representación las diferentes alternativas frente a estas situaciones límites de lo humano, donde cada cual elige el personaje y la situación con la que siente mayor empatía. Curiosidad y empatía juegan así un rol importante en el hecho de situarse ante la representación del dolor.

Ésta puede darse como una instancia que posibilita canalizar el propio sufrimiento, lo viabiliza en tanto catarsis personal, pero incluso también en un sentido social. De allí el sentido no sólo estético, sino además moral y catártico de la tragedia. Uno se sitúa en el lugar hipotético de ese otro, del que sufre, se lo comprende, se lo ayuda y se aprende. $\mathrm{Y}$ es justamente este lugar hipotético, este "como si", propio de la representación lo que permite el juego de distancia y proximidad en relación al dolor del otro.

Atrée et Thyeste, tragedia escrita por Crébillon en 1707.

14 ROUSSEAU, J.J. Discurso sobre el origen y los fundamentos de la desigualdad entre los hombres. Tecnos. Madrid. 1995. pág. 258. 
La representación estética del dolor abre la posibilidad de comprender el sufrimiento del otro, donde el otro es aquel que se nos aparece, que está, que existe, que no se puede ocultar, que tiene rostro. Pero que a su vez es absolutamente otro y por ello inabarcable. Nos desborda en su totalidad y no se puede lograr una identificación con él, o no por lo menos en el sentido de identidad. Solo resta abrirse sosteniéndose en el respeto y la pasividad. ${ }^{15}$

Pasividad que nos suena extraña, o que por lo menos debería presentarse como tensión, ya que entre la disposición natural de piedad que nos demanda un desplazamiento y el respeto por el dolor de este absolutamente otro, la distancia y el desconcierto es muy grande. Se considera, a partir del planteo de Levinas, que si bien el otro y su dolor son absolutamente inabarcables, por ser justamente totalmente otro, esto no implica un respeto o una pasividad rayana en la indiferencia. Más bien todo lo contrario. Debe destacarse así que el otro en Levinas es un otro previo a la constitución misma del sujeto, ya que éste lo constituye. Se estaría situado aquí en una dimensión ontológica previa a la del sujeto constituido del que habla Rousseau.

Se podría pensar entonces que este profundo acercamiento excede la relación distancia-proximidad, puesto que se llega a la mismísima intimidad en la que el otro es constitutivo del yo, donde el yo es absolutamente responsable del otro, llegando a ser rehén ${ }^{16}$ del mismo. Esta constitución del yo por la alteridad genera la imposibilidad de la indiferencia. No se puede evadir al otro porque no sólo se nos aparece, sino que primordialmente nos constituye. Se sostiene aquí la tensión entre nuestra absoluta responsabilidad por el otro y su absoluta otredad, situación que por un lado nos ata a él, pero que por el otro nos distancia y limita la posibilidad de abarcarlo, de ponernos

15 LEVINAS, Emmanuel. Totalidad e Infinito. Ensayo sobre la exterioridad, Sígueme. Salamanca. 1971.

16 Cfr. LEVINAS, Emmanuel. De la existencia al existente. Arena. Madrid. 2000, donde desarrolla extensamente la categoría de rehén. 
en su lugar. Se permanece responsablemente allí, pero sin invadir su vivencia -porque aun queriéndolo, tal cosa no sería posible-.

Frente al espectáculo del dolor del otro se nos presenta la cuestión de qué hacer frente a él. El dolor exige acción, tanto física como psíquica, por lo que debo responder a esta demanda. No obstante, nos encontramos en el dilema de que si dejamos de ser espectadores frente a este, si nos ponemos en marcha por medio de la piedad corremos el riesgo de avasallar al otro en su dolor, de no dejarle lugar, de anular su tiempo y espacio y terminar echándolo de su propio dolor.

No puede haber un ponerse en el lugar del otro, en su horror, eso es obsceno, eso es dejarlo fuera de la escena, ocultarlo, pero no ya en el sentido de protección del espectador ni de la belleza o justeza de la obra, sino por un avasallamiento de su espacio, de su representación, de su dolor y su realidad. Quizás porque a su vez se reemplaza su dolor, su horror por uno bajo nuestros parámetros y cánones, por aquel que sí se esté dispuesto a tolerar, a ver y, por qué no, socorrer.

Se debería en cambio poder sostener el rol de espectador, no completamente distante y desinteresado -como la actitud del sabio en Lucrecio $^{17}$-, sino en actitud de pasiva pero atenta escucha. Lograr el espacio donde pueda preguntársele al otro "¿cuál es tu dolor?, ¿en qué consiste ese dolor que no es el mío?", lo que implicaría sin duda plantear el problema de un modo diferente.

Buscar esa tensión "distancia-proximidad" que se nos presenta en el círculo hermenéutico, asumir esta perspectiva de ida y vuelta permanente. No implica esto una reiteración viciosa, un ir y venir desde uno hacia lo mismo, sino que se apuesta al círculo que se perfecciona, a aquel que presenta un permanente ir y venir en el que tanto uno como el otro-aquel que ya no es lo mismo que uno, si no ese absolutamente

17 Aunque la distancia del espectador lograda por el sabio en Lucrecio sea producto del trabajo, en la búsqueda de la ataraxia como virtud. 
otro- se modifican, y continúan haciéndolo en esta tensión de ida y vuelta, de distancia y proximidad, de la relación "yo - otro".

Así junto con Levinas se asume el respeto por el otro, por su palabra, por su dolor y se dispone a la escucha, a partir de la cual quizás se pueda pensar y practicar una hermenéutica de la escucha del dolor del otro.

\section{IV}

Sin embargo, debemos tener en cuenta que este dolor es planteado aquí en relación a su representación. El artista se presenta como aquel que al reflexionar sobre el dolor lo redimensiona, lo decodifica a modo de diagnóstico y puede representarlo mediante un lenguaje diferente. Frente al dolor, a lo horroroso, la decodificación del artista posibilita un acercamiento puesto que se priva al dolor de su "terror" y se busca que este dolor sea "bello"18.

Este acercamiento puede permitir una mejor comprensión del dolor del otro, un otro modo de comprensión a través de la representación estética. Quizás puedo no ponerme específicamente en su lugar sino intentar este juego de ida y vuelta, a modo de círculo hermenéutico, porque está codificado estéticamente, porque está representado de un modo justo. El arte puede ser este punto intermedio entre la proximidad y la distancia con el otro, entre el avasallamiento de su dolor y la indiferencia.

El sufrimiento y el horror como aquello presente, que no puede ser negado, que no puede ser dejado fuera de escena, puesto que es parte

18 La belleza como fin de la representación y del arte en general es una opción dentro de otras. Sabido es ya que no se erige como "el" paradigma en el arte actual, sino que de hecho se ha buscado correrlo u opacarlo de diferentes modos. En el presente trabajo haremos hincapié más en el "modo justo" de la representación que en la belleza de la misma. Ésta no se postula como canon o adecuación, sino como solución plástica justa capaz de hacer visible el horror y de limitar la clase de fealdad que presenta el asco -único sentimiento que según Kant no es representable bellamente ya que no produce satisfacción estética (Cfr. Crítica del Juicio, parágrafo 48)-. 
fundamental que nos constituye, se hace presente por medio del arte. La representación posibilita una visión más amena, un permanecer allí en un intento de comprensión. Es posible observar, escuchar al otro en su dolor, sin la imperiosa necesidad de correr en su auxilio para modificar la situación de horror que se presenta, y sin tampoco querer huir de ello. Al recodificarse el horror por medio del arte, el juego se amplía y la relación puede ser planteada de otro modo.

El arte se sostiene así no sólo como forma de expresión sino a su vez como forma de conocimiento de este otro y su dolor. La sensibilidad se presenta en esta relación como quien posibilita la conexión entre lo corporal y lo intelectual ${ }^{19}$, donde la comprensión del otro adquiere diferentes dimensiones, puesto que "pongo el cuerpo" por el otro. Ya no se trata únicamente de una comprensión racional, sino de una modificación de nuestra sensibilidad que se abre frente a este otro dolor.

Este "poner el cuerpo" si bien es una respuesta frente a la demanda de acción que exige el dolor, mantiene aún una distancia. Nos corremos aquí de la piedad -o por lo menos en el sentido que le dimos anteriormente- ya que si bien ésta nos auxilia en el dolor, en lo tenebroso, en lo inhumano, en lo amorfo, deberíamos preguntarnos hasta qué punto no lo oculta, no lo deja fuera de escena, obscenamente, convirtiendo lo amorfo en belleza, intentando sellar de una vez la grieta, la abertura, la falta originaria, como una especie de conjuro de aquello negado.

Escribe así Kusch en sus Anotaciones para una estética de lo americano:

"El arte se vuelca con violencia, como venciendo una resistencia, ya que expresa contenido que adopta una forma. (...) En este punto asoma lo tenebroso en el arte. Porque se fija y

19 No debe entenderse esta posibilidad de conexión, dada por la sensibilidad, como la afirmación de un dualismo antropológico, sino más bien como un momento analítico. 
se contiene en arte una vida postergada frente a lo social. 0 sea, se vuelve a traducir en formas o en signos comprensibles aquello que socialmente fue excluido o relegado como algo tenebroso frente a la inteligencia social. Mientras el cuerpo social deambula dentro de su propia estructura intelectual, la vida le cuestiona sus derechos por intermedio del arte"20.

Esta vida que cuestiona por medio del arte, este contenido que adopta una forma produce una reinterpretación no sólo del contenido sino también de la forma misma, en el fondo reinterpretación de la vida, que representada estéticamente genera una mayor decibilidad del dolor y una mejor apertura a la escucha del mismo.

Sin embargo, aunque esta representación del dolor que se sostiene genera una apertura, presenta también sus límites. Sólo porque la piedad se pone en marcha puede emerger la belleza en las representaciones del dolor, lo que implica a su vez que la belleza funcione como salvataje de lo inhumano en nosotros mismos, contra aquello que no tiene forma. Así la piedad puede conducir al terror.

\section{V}

Auschwitz en este sentido marca no sólo uno de los mayores horrores contemporáneos, sino consecuentemente un redimensionamiento del dolor, como así también de su representación. El campo se sitúa como el paradigma del horror, a partir del cual el resto se configura.

Más allá de la discutida frase de Adorno ${ }^{21}$, se afirma la posibilidad del arte después del horror -como así también a causa del mismo- pero ya no bajo los mismos parámetros de creación, sino como un nuevo

$20 \mathrm{KUSCH}$, Rodolfo. Anotaciones para una estética de lo americano. En: Obras Completas. Tomo 4. Editorial Fundación Ross. Buenos Aires. 2007. Pág. 532.

21 Posteriormente Adorno contextualiza y explica su afirmación, donde queda manifiesta su intención de en absoluto negar la posibilidad del arte después de Auschwitz. 
modo de representación atravesado por este horror que cambió completamente su forma.

Es así que junto con Imre Kertesz se sostiene la posibilidad de un arte "con" Auschwitz, donde no se puede "vender" el horror a cualquier precio, donde el dolor no se teatraliza banalmente, sino que se busca que la representación sea aquello que ayuda a comprender lo que pasó, que se abre a la compresión del horror pero sin buscar piedad, porque no es posible este "ponerse en lugar de". Esta especie de sustitución sería obscena en todos los sentidos. Se desplazaría a la víctima de su dolor por una posibilidad de "reemplazo" completamente inexistente. Se dejaría al otro fuera de la escena porque somos incapaces de ver su dolor.

Se busca una solución plástica justa que no implique ni el "ponerse en el lugar de" propio de la piedad, ni el dejarlo fuera de escena, donde sólo se muestra la parte que se está dispuesto a ver, donde se observa la representación sin hacerse cargo de lo obsceno de la misma, de aquel horror que se dejó atrás de la escena, pero que necesita ser mostrado, aun a pesar de la distancia entre el lenguaje del que se dispone y la experiencia que aún se marca en el cuerpo.

No se puede escapar, aun cuando no se hable "de" siempre se está "con" Auschwitz. De allí que se necesiten nuevos modos de creación, donde no se trata de hacer del horror un tema de emoción, sino de que estas nuevas representaciones ayuden a abrir la posibilidad de comprender lo que pasó, de comprender el dolor del otro.

El estar siempre "con" implica entonces repensar nuestra misma humanidad y hacerse cargo de la inhumanidad que no es lejana y ajena, sino que nos es propia. Aquello que no queremos ver se nos hace presente a través de la representación. Surge como aquello negado de lo que hablaba Kusch, que nos impele a asumir lo amorfo que nos constituye.

Como bien señala Marcelo Viñar presentando La especie humana de Robert Antelme: 
De Antelme (también de Freud y Foucault) aprendimos que pensar la civilización no es sólo estudiar su expansión y progreso sino reconocer y tramitar su reverso, sórdido y siniestro. Que ese reverso dice de nosotros algo esencial, dice justo lo que no queremos ver. ${ }^{22}$

\section{Bibliografía}

ANTELME, Robert. La Especie Humana. Lom Ediciones. Santiago de Chile. 1999.

CICERÓN. Sobre la Naturaleza de los dioses. En: http://books.google.com/ books?id=2YoA7dFccDsC\&printsec=frontcover\& $d q=c i c e r o n+$ sobre+la + natu

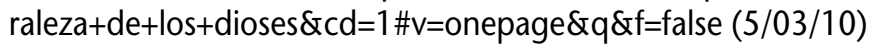

FERNÁNDEZ G., Eugenio. "Una "mística" que se hace política: La piedad en Spinoza". En: Fernández Vallina, Javier y otros. Pensamiento y mística hispanojudía y sefaradí. Universidad de Castilla-La Mancha. Toledo. 2001.

GOLDWASER YANKELEVICH, Natalie. La Piedad: excusa para un diálogo maejor. 2005. En http://www.a-r-w-e-b.com.ar/isociologia (12/12/09)

GIBERTI, Eva. Piedad, compasión y justicia. En: Página/12, Buenos Aires, 21 de septiembre. 2001.

KANT, Immanuel. Crítica del Juicio. Traducción: Manuel García Morente. Editorial Espasa Calpe. Madrid. 2007.

KERTESZ, Imre. http://nobelprize.org/nobel_prizes/literature/laureates/2002/ kertesz-article.html (10/08/2010)

$\mathrm{KUSCH}$, Rodolfo. Anotaciones para una estética de lo americano. En: Obras Completas. Tomo 4. Editorial Fundación Ross. Buenos Aires. 2007.

LEVINAS, Emmanuel. Totalidad e Infinito. Ensayo sobre la exterioridad. Sígueme. Salamanca. 1971.

LEVINAS, Emmanuel. Diálogo con Levinas: Ética e infinito (§ 8). En: http:// espacethique.free.fr/articles.php?Ing=fr\&pg=176 (1/04/10)

LEVINAS, Emmanuel. De la existencia al existente. Arena. Madrid. 2000.

NIETZSCHE, Friedrich. El origen de la tragedia. Espasa-Calpe. Madrid. 1975.

22 Antelme Robert. La Especie Humana. Lom Ediciones. Santiago de Chile. 1999. pág. 15. 
ROUSSEAU, J.J. Obras Escogidas. Ed. El Ateneo. Buenos Aires. 1950.

ROUSSEAU, J.J. Discurso sobre el origen y los fundamentos de la desigualdad entre los hombres. Tecnos. Madrid. 1995.

SAVATER, F. "La humanidad en cuestión", en La secularización de la Filosofía. Hermenéutica y posmodernidad, Gedisa Editorial. Barcelona. 1992.

STAROBINSKI, J. Jean Jacques Rousseau. La transparencia y el obstáculo, Taurus Ediciones, Madrid. 1983.

http://www.elalmanaque.com/politica/OBSCENIDAD.htm (20/03/10)

http://www.perseus.tufts.edu/hopper/resolveform?redirect=true\&lang=La $\operatorname{tin}(26 / 03 / 10)$

www.rae.es $(30 / 03 / 10)$ 